\title{
Analisis Kelayakan Pemasangan Load Break Switch (LBS) Penyulang Rindik Pada Proses Manuver Antar Penyulang Di PLN ULP Toboali
}

\author{
Syarifah $^{1}$, Rudy Kurniawan ${ }^{1 *}$, Asmar $^{1}$ \\ Jurusan Teknik Elektro, Fakultas Teknik, Universitas Bangka Belitung ${ }^{1}$ \\ *Email : rudy14k@gmail.com
}

\begin{abstract}
The electric power distribution system is very important for the distribution of electricity to consumers, especially for the continuity of voltage and power services. Currently, due to the maintenance / maintenance of Circuit Breakers in the Rindik feeders, it is necessary to maneuver the load by installing an LBS Load Break Switch (LBS) between the two feeders. From that it is necessary to do an analysis of the power flow between the existing conditions and after the maneuver, obtained based on the Software Simulation in the first condition seen from the end voltage of the Bencah feeder, which is 19,423 $\mathrm{kV}$, with power losses of $0.129 \mathrm{MW}$. The results of the second condition power flow can be seen at the tip voltage at the Bencah feeder, which is $18,153 \mathrm{kV}$ with a power loss of $0.294 \mathrm{MW}$. And the simulation results. The third condition of the power flow can be seen from the tip of the Bencah feeder and the City turtle, the value of the end of the Bencah feeder is $18,969 \mathrm{kV}$ and the tip voltage at the City feeder is 19,395 $\mathrm{kV}$ with a total power loss of $0.304 \mathrm{MW}$. Judging from the results of the 3 simulation simulation results, the maneuvering load that produces a good end voltage, and has the most small power losses, is in the first condition maneuver simulation so that it can be stated Load Brek Switch (LBS) Gang asem the first condition is feasible to install.
\end{abstract}

Keywords : Rindik Feeder, Bencah Feeder and Kota Feeder, Load Maneuver, Distribution Network, Load Break Switch

\section{INTISARI}

Sistem distribusi tenaga listrik merupakan hal yang sangat penting terhadap penyaluran listrik ke konsumen, terutama pada kontinyuitas pelayanan tegangan dan daya. saat ini dikarena adanya maintenence circuit Breaker pada penyulang Rindik, maka penyulang Rindik harus dilakukan manuver beban dengan pemasangan Load Break Switch diantara kedua penyulang. dari itu perlu dilakukan analisis mengenai aliran daya antara kondisi eksisting dan sesudah manuver, didapatkan berdasarkan Simulasi Software pada kondisi pertama dilihat dari tegangan ujung penyulang Bencah yaitu 19,423 kV, dengan Rugi-rugi daya sebesar 0,196 MW. Hasil aliran daya kondisi kedua dapat dilihat pada tegangan ujung pada penyulang Bencah yaitu sebesar $18,153 \mathrm{kV}$ dengan rugi daya sebesar 0,294 MW dan Hasil Simulasi Software kondisi ketiga aliran daya dapat dilihat dari ujung penyulang Bencah dan penyulang Kota, nilai tegang ujung penyulang Bencah yaitu sebesar 18,769 kV dan tegangan ujung pada penyulang Kota yaitu sebesar 19,395 kV dengan rugi daya keseluruhan yaitu sebesar 0,304 MW. Dilihat dari hasil simulasi 3 kondisi simulasi manuver yang dilakukan, manuver beban yang menghasilkan tegangan ujung yang baik, serta memiliki rugi-rugi daya yang paling kecil, adalah pada simulasi manuver kondisi pertama sehingga dapat dinyatakan Load Break Switch Gang asem kondisi pertama layak untuk dipasang.

Kata kunci: Penyulang Rindik, Penyulang Kota, Penyulang Bencah, Manuver Beban, Jaringan Distribusi, Load Break Switch

\section{PENDAHULUAN}

Analisis aliran daya ialah analisis yang digunakan untuk menentukan dan menghitung tegangan, arus, daya, dan faktor daya atau daya reaktif yeng terdapat pada berbagai titik dalam suatu jaringan listrik pada keadaaan pengoperasian normal, baik yang sedang berjalan maupun yang diharapkan akan terjadi di masa yang akan datang. Analisis aliran daya sangat penting dalam dalam perencanaan pengembangan suatu sistem tersebut banyak tergantung pada efek interkoneksi dengan sistem tenaga yang lain, beban yang baru, stasiun pembangkit baru, serta saluran transmisi baru, sebelum semuanya dipasang (Stevenson, 1983).

PLN adalah perusaan BUMN yang bertugas untuk memenuhi kebutuhan listrik, di tuntut untuk 
menyediakan energi listrik yang cukup, baik secara kuantitas maupun kualitas . PLN harus mampu menjawab tantangan ini dengan peningkatan pelayanan dan penyediaan energi listrik. Listrik yang di salurkan ke pelanggan harus secara kontinyu, aman,dan efisiendalam biaya pengoperasiannya, PLN harus menjaga penyaluran tenaga listrik kepada pelanggan sehingga tidak padam. Namun karena sistem kelistrikan yang sangat kompleks, mulai dari pusat pembangkit hingga sampai ke konsumen, maka tidak dipungkiri dalam penyaluran listrik ke pelanggan akan berjalan mulus $100 \%$ tanpa adanya gangguan yang bisa menyebabkan aliran daya ke konsumen terputus, pemutusan aliran listrik tersebut juga bisa di akibatkan karena adanya pemadaman yang sudah terjadwal oleh PLN untuk suatu perkerjaan pemeliharaan jaringan. Namun pada konsumen tentu yang termasuk dalam golongan VIP seperti pabrik, rumah sakit,industri menengah, sehingga aliran listrik tidak boleh terputus dalam waktu yang lama karena dapat menghambat proses kegiatan perusahaan, sehingga membutukan suplai cadangan untuk mengantisipasi ketika aliran daya dari jaringan listrik utama terputus. Diperlukan penanganan untuk mengurangi area pemadaman listrik karena adanya maintenence/ pemeliharaan circuit Breaker. Salah satu caranya dengan melakukan manuver beban pada jaringan distribusi. Manuver adalah teknik menipulasi jaringan dengan membuka atau menutup peralatan Switching pada jaringan untuk membatasi wilayah padam sesuai degan kebutuhan

Berdasarkan kondisi kelistrikan sistem saat ini dikarena adanya maintenence/ pemeliharaan circuit Breaker pada penyulang rindik, pihak PLN sedang berencana menabahkan Load Break Switch dengan cara melakukan manuver beban pada penyulang Rindik dari itu perlu dilakukan analisis mengenai aliran daya antara kondisi eksisting dan sesudah manuver pada penyulang Rindik di PLN ULP Toboali. penyulang distribusi yang menjadi objek penelitian adalah Penyulang Rindik. objek manuver yang akan dilakukan yaitu pada penyulang Bencah dan Penyulang Kota yang Di Pasok dari PLTD Toboali . yang dimana Penyulang Rindik akan di manuver ke penyulang Bencah dan penyulang Rindk manuver ke penyulang bencah dan Penyulang Kota, dengan menambahkan LBS diantara Kedua penyulang

Harapan setelah penelitian ini adalah didapatkannya aliran daya tegangan ujung dan rugirugi yang baik sebelum dan setelah pemasangan Load
Break Switch, agar dapat disimpulkan layak atau tidaknya pemasangan Load Break Switch tentang "Analisis Kelayakan Pemasangan Load Brak Switch Penyulang Rindik pada proses Manuver antar penyulang di PLN ULP Toboali". Penelitian ini menggunakan software simulasi sistem tenaga listrik untuk mempermudah dan mempercepat dalam proses perhitungan aliran daya.

\section{LANDASAN TEORI}

\section{A. Sistem Tenaga Listrik}

Sistem tenaga listrik merupakan suatu kesatuan yang terintegrasi mulai dari pembangkit, transmisi, sampai distribusi dalam upaya menyalurkan listrik dari produsen kepada konsumen. Ada tiga bagian penting dalam proses penyaluran tenaga listrik, yaitu

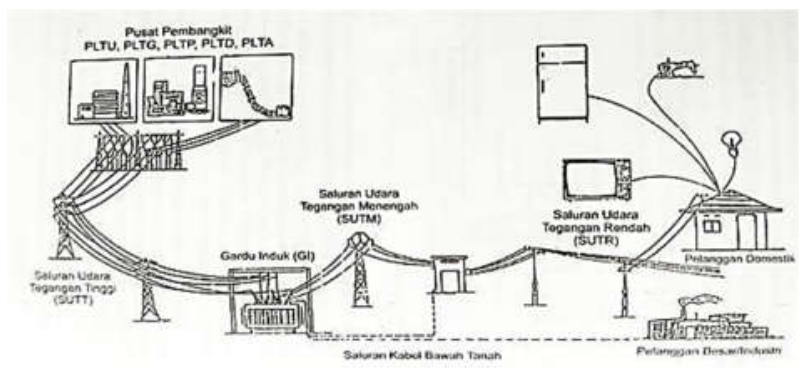

pembangkitan, penyaluran (transmisi), dan distribusi. Sistem tenaga listrik di perlihatkan pada Gambar 1.

\section{Gambar 1. Sistem Tenaga Listrik}

Tenaga listrik dibangkitkan dalam pusat- pusat listrik seperti PLTA, PLTU, PLTG, PLTP, dan PLTD. Nominal tegangan pada generator besar biasanya berkisar antara $13,8 \mathrm{kV}$ sampai $24 \mathrm{kV}$. Tidak ada standar umum yang dibuat untuk tegangan generator. Kemudian disalurkan melalui saluran transmisi setelah terlebih dahulu dinaikkan tegangannya oleh transformator penaik tegangan (step up transformer) yang ada di pusat pembangkit. Menurut nominal tegangannya, saluran transmisi dibagi menjadi 3 yaitu saluran udara tegangan tinggi yang nominalnya 115 , 138 dan $230 \mathrm{kV}$, saluran udara tegangan ekstra tinggi yang nominal tegangannya 345, 500 dan $765 \mathrm{kV}$ serta saluran udara tegangan ultra tinggi yang nominal tegangannya berkisar antara $1000-1500 \mathrm{kV}$. Saluran transmisi tegangan tinggi di PLN kebanyakan mempunyai tegangan $66 \mathrm{kV}, 150 \mathrm{kV}$, dan $500 \mathrm{kV}$. Saluran transmisi ada yang berupa saluran udara dan ada pula yang berupa kabel tanah. 


\section{B. Sistem Distribusi}

Sistem distribusi adalah keseluruhan komponen dari sistem tenaga listrik yang menghubungkan secara langsung antara sumber daya yang besar (seperti gardu transmisi) dengan konsumen tenaga listrik. Secara umum yang termasuk ke dalam sistem distribusi antara lain:

1. Gardu Induk (GI)

2. Jaringan Subtransmisi

3. Gardu Distribusi Utama

4. Saluran Penyulang Utama

5. Transformator Distribusi

6. Rangkaian Sekunder

\section{Load Break Switch (LBS)}

Saklar pemutus beban (Load Break Switch/LBS) merupakan saklar atau pemutus arus tiga phasa untuk penempatan di luar ruas pada tiang panjang, yang di kendalikan secara manual maupun secara elektronis. Load break switch (LBS) mirip dengan alat pemutus tegangan (PMT) atau Circuit Breaker (CB) dan biasanya di pasang dalam saluran disribusi listrik.

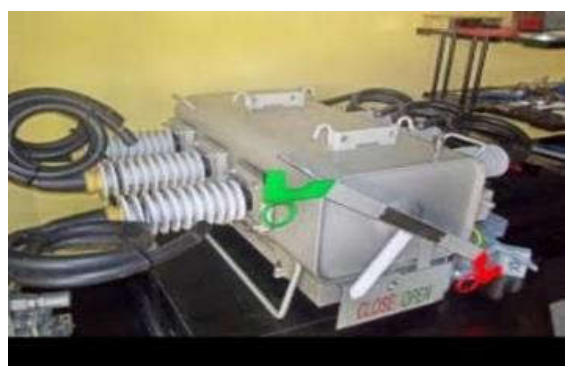

Gambar 2. Load Break Switch (LBS)

D. Jenis Penghantar Tegangan Menengah

Bahan konduktor yang paling umum digunakan adalah tembaga dan aluminium serta aluminium campuran. Dilihat dari jenis isolasi yang digunakan, konduktor terdiri dari dua jenis yaitu konduktor atau kawat telanjang dan konduktor berisolasi (XLPE).

Khusus untuk transmisi umumnya digunakan beberapa jenis penghantar yaitu: AAC (All Alluminium Conductor), AAAC(All Alluminium Alloy Conductor), ACSR (Alluminium Conductor Steel Reinforced), dan ACAR (Alluminium Conductor Alloy Reinforced).

\section{E. Metode Newton Raphson}

Untuk menerapkan metoda Newton-Raphson pada penyelesaian persamaan aliran beban kita dapat memilih untuk menyatakan tegangan rel dan admitansi saluran dalam bentuk polar atau bentuk siku-siku. Jika persamaan berikut:

$$
P_{k}-j Q_{k}=V_{k}^{*} \sum_{n=1}^{N} Y_{k n} V_{n}
$$

Dipilih bentuk polar dan kita uraikan persamaan (1) ke dalam unsur nyata dan khayalnya dengan

$$
\begin{array}{r}
V_{k}=\left|V_{k} \angle \delta_{k} \quad V_{n}=\right| V_{n} \angle \delta_{n} \\
Y_{k n}=\left|Y_{k n}=\right| Y_{k n} \mid \angle \theta_{k n}
\end{array}
$$

selanjutnya,

$$
P_{k}-j Q_{k}=\sum_{n=1}^{N}\left|V_{k} V_{n} Y_{k n}\right| \angle \theta_{k n}+\delta_{n}-\delta_{k}
$$

maka,

$$
\begin{gathered}
P_{k}=\sum_{n=1}^{N}\left|V_{k} V_{n} Y_{k n}\right| \cos \left(\theta_{k n}+\delta_{n}-\delta_{k}\right) \\
Q_{k}=-\sum_{n=1}^{N}\left|V_{k} V_{n} Y_{k n}\right| \sin \left(\theta_{k n}+\delta_{n}-\delta_{k}\right)
\end{gathered}
$$

Seperti pada metoda Gauss-Seidel rel berayun diabaikan dari penyelesaian iterasi untuk menentukan tegangan, karena baik besar tegangan maupun sudut tegangan pada rel tersebut telah ditentukan. Jika untuk sementara kita tunda pembahasan rel-rel dengan pengaturan-tegangan, kita dapat menentukan $\mathrm{P}$ dan $\mathrm{Q}$ pada semua rel kecuali rel berayun dan memperkirakan besar dan sudut tegangan pada setiap rel kecuali rel berayun di mana besar dan sudut tegangan sudah ditetapkan. Kita gunakan nilai perkiraan ini untuk menghitung nilai Pk dan Qk dari Persamaan (5) dan (6) dan mendefinisikan :

$$
\begin{aligned}
& \Delta P_{k}=P_{k, \text { spec }}-P_{k, \text { calc }} \\
& \Delta Q_{k}=Q_{k, \text { spec }}-Q_{k, \text { calc }}
\end{aligned}
$$

Subskrip "spec" berarti "yang ditetapkan" (specified) sedangkan "calc" berarti "yang dihitung" (calculated).

Jacobian terdiri dari turunan parsial $\mathrm{P}$ dan $\mathrm{Q}$ terhadap. masing-masing variabel dalam Persamaan (5) dan (6). Unsur-unsur matriks kolom $\Delta \delta_{k}^{(0)}$ dan $\Delta\left|V_{k}\right|^{(0)}$ bersesuaian dengan $\Delta x_{1}{ }^{(0)}$ dan $\Delta x_{2}{ }^{(0)}$ dan merupakan koreksi yang harus ditambahkan pada perkiraan semula $\delta_{k}{ }^{(0)}$ dan $\left|V_{k}\right|^{(0)}$ untuk mendapatkan nilai baru bagi perhitungan $\Delta P_{k}^{(1)}$ dan $\Delta Q_{k}^{(1)}$.

Untuk penyederhanaannya akan kita tuliskan persamaan matriks untuk suatu sistern yang terdiri hanya dari tiga buah rel. Jika rel berayun adalah nomor 1, perhitungan kita mulai pada rel 2 karena besar dan sudut tegangan sudah ditentukan pada rel berayun. Dalam bentuk matriks. 


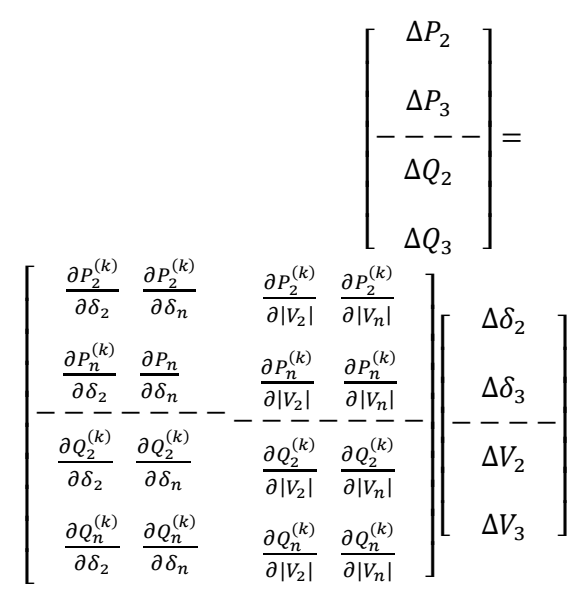

Tanda yang biasanya menunjukkan nomor iterasi telah ditiadakan dalam persamaan (9) karna sudah tentu, nomor-nomor tersebut berubah pada setiap iterasi. Unsur Jacobian diteroleh dengan membuat turunan parsial dari rumus untuk $\mathrm{P}_{\mathrm{k}}$ dan $\mathrm{Q}_{\mathrm{k}}$ dan memasukkan ke dalamnya tegangan-tegangan yang diperkirakan untuk iterasi pertama atau yang diperhitungkan dalam iterasi yang terdahulu dan terakhir. Jacobian itu telah disekat untuk memperjelas adanya bermacam-macam jenis umum turunan parsial yang muncul pada masing-masing submatriks. Misalnya, dari persamaan (5) kita dapatkan:

$$
\frac{\partial P_{k}}{\partial \delta_{n}}=-\left|V_{k} V_{n} Y_{k n}\right| \sin \left(\theta_{k n}+\delta_{n}-\delta_{k}\right)
$$

dengan $\mathrm{n} \neq \mathrm{k}$ dan

$$
\frac{\partial P_{k}}{\partial \delta_{n}}=\sum_{\substack{n=1 \\ n \neq k}}^{N}\left|V_{k} V_{n} Y_{k n}\right| \sin \left(\theta_{k n}+\delta_{n}-\delta_{k}\right)
$$

Dalam penjumlahan di atas, jelas bahwa $\mathrm{n} \neq \mathrm{k}$ karna $\delta_{\mathrm{k}}$ akan hilang dari persamaan (9) jika $\mathrm{n}=\mathrm{k}$. Bentuk umum yang serupa dari turunan parsial dapat diperoleh dari persamaan (10) dan (11) untuk menghitung unsur-unsur pada submatriks yang lain.

Persamaan (9) dan persamaan serupa yang menyangkut rel-rel yang lebih banyak diselesaikan dengan membalikkan Jacobian. Nilai yang didapatkan untuk $\Delta \delta_{\mathrm{k}}$ dan $\Delta\left|\mathrm{V}_{\mathrm{k}}\right|$ ditambah pada nilai terdahulu daro besar dan sudut tegangan untuk mendapatkan nilai baru untuk $\mathrm{P}_{\mathrm{k}, \text { calc }}{ }^{(1)}$ dan $\mathrm{Q}_{\mathrm{k}, \text { calc }}{ }^{(1)}$, untuk memnulai iterasi berikutnya. Proses ini diulangi hingga indeks ketepatan yang diterapkan pada kuantitas di kedua matrikas kolom telah terpenuhi. Tetapi untuk mencapai kovergensi perkiraan pertama tentang tegangan harus cukup mendekati kenyataan.
Rel-rel dengan tegangan yang diatur dapat diperhitungkan dengan mudah. Karna pada rel semacam itu besarnya tegangan konstan, kolom diferensial parsial terhadap besar tegangan real itu dihilangkan dalam Jacobian. Pada tahap ini kita tidak berminat pada nilai Q dari rel itu, jadi kita hilangkan pula baris diferensial parsial dari Q untuk rel dengan pengaturan tegangan itu. Nilai Q pada rel itu dapat ditentukan setelah konvergensi dari persamaan (6).

\section{METODE PENELITIAN}

Untuk memudahkan penelitian maka dibuatlah diagram alir langkah penelitian. Adapun diagram alir langkah penelitian dapat dilihat pada Gambar 3.

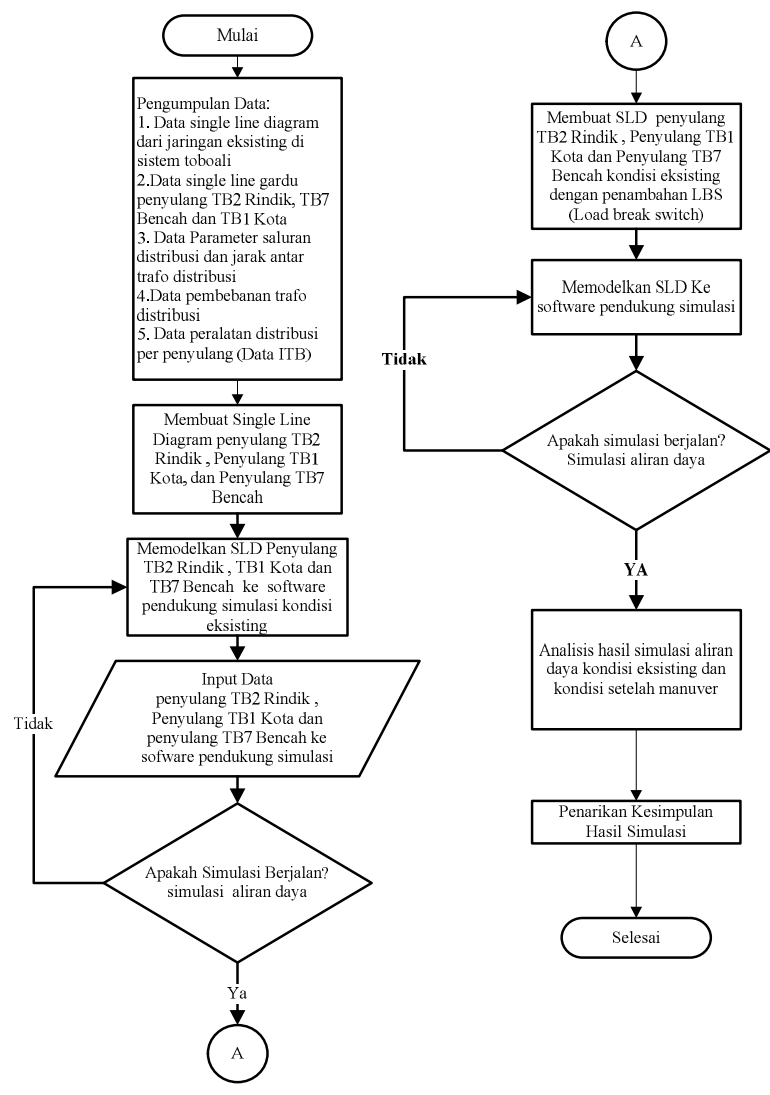

Gambar 3. Langkah Penelitian 


\section{HASIL PENELITIAN DAN PEMBAHASAN}

\section{A. Hasil Perhitungan dan Simulasi}

Penyelesaian aliran daya dengan metode NewtonRaphson.

$$
\left[\begin{array}{c}
\Delta P_{2} \\
\Delta P_{3} \\
--- \\
\Delta Q_{2} \\
\Delta Q_{3}
\end{array}\right]=\left[\begin{array}{cccc}
\frac{\partial P_{2}^{(k)}}{\partial \delta_{2}} & \frac{\partial P_{2}^{(k)}}{\partial \delta_{n}} & \frac{\partial P_{2}^{(k)}}{\partial\left|V_{2}\right|} & \frac{\partial P_{2}^{(k)}}{\partial\left|V_{n}\right|} \\
\frac{\partial P_{n}^{(k)}}{\partial \delta_{2}} & \frac{\partial P_{n}}{\partial \delta_{n}} & \frac{\partial P_{n}^{(k)}}{\partial\left|V_{2}\right|} & \frac{\partial P_{n}^{(k)}}{\partial\left|V_{n}\right|} \\
\hdashline-\frac{\partial Q_{2}^{(k)}}{\partial \delta_{2}} & \frac{\partial Q_{2}^{(k)}}{\partial \delta_{n}} & \frac{\partial Q_{2}^{(k)}}{\partial\left|V_{2}\right|} & \frac{\partial Q_{2}^{(k)}}{\partial\left|V_{n}\right|} \\
\frac{\partial Q_{n}^{(k)}}{\partial \delta_{2}} & \frac{\partial Q_{n}^{(k)}}{\partial \delta_{n}} & \frac{\partial Q_{n}^{(k)}}{\partial\left|V_{2}\right|} & \frac{\partial Q_{n}^{(k)}}{\partial\left|V_{n}\right|}
\end{array}\right]\left[\begin{array}{c}
\Delta \delta_{2} \\
\Delta \delta_{3} \\
-\Delta V_{2} \\
\Delta V_{3}
\end{array}\right]
$$

Hasil simulasi software kondisi eksisting penyulang Rindik single line diagram pada software dibuat lebih sederhana. Nilai rugi daya kondisi eksisting dapat dilihat pada Gambar 4.

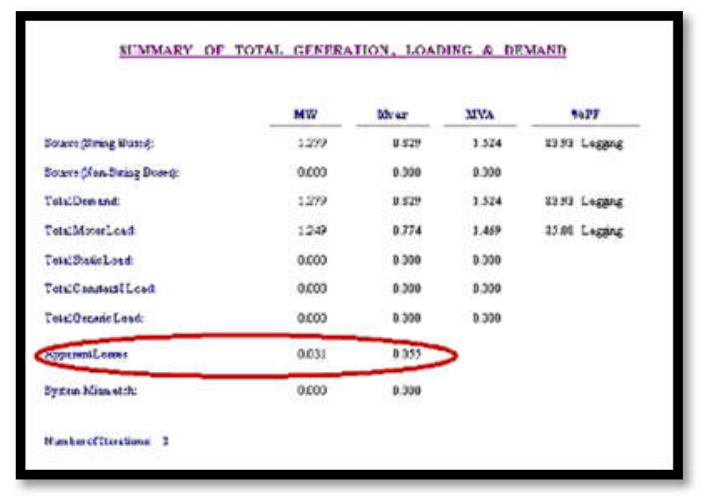

Gambar 4. Summary report kondisi eksisting penyulang Rindik

Dari Gambar 4 dapat diketahui dari simulasi summry report pada software penyulang rindikdiperoleh rugi-rugi daya aktif $31 \mathrm{~kW}$ dan rugi daya reaktif 55 kvAr. Rugi-rugi daya tersebut dipengaruhi oleh panjang saluran dan luas panjang kawat penghantar. Nilai rugi-rugi ini relatif tinggi untuk daya yang hilang. Namun PLN sendiri tidak memiliki standar untuk nilai rugi-rugi daya maksimal yang di izinkan dalam suatu jaringan. hanya meminimalisir sekecil mungkin agar memperkecil kerugian pada perusahaan.

\section{B. $\quad$ Kondisi Eksiting Penyulang Rindik}

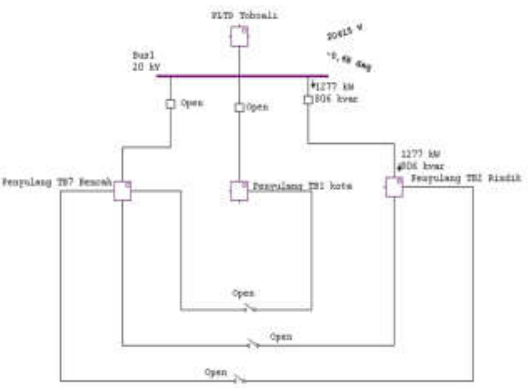

Gambar 5. Hasil Simulasi software kondisi eksisting penyulang Rindik

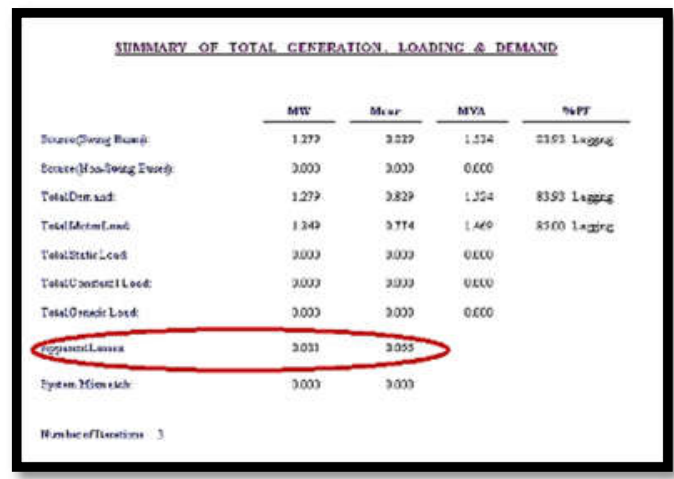

Gambar 6. Summary report kondisi eksisting penyulang Rindik

Dari Gambar 4 dan 5 dapat diketahui dari simulasi summry report pada software penyulang rindikdiperoleh rugi-rugi daya aktif $31 \mathrm{~kW}$ dan rugi daya reaktif 55 kvAr. Rugi-rugi daya tersebut dipengaruhi oleh panjang saluran dan luas panjang kawat penghantar. Nilai rugi-rugi ini relatif tinggi untuk daya yang hilang. Namun PLN sendiri tidak memiliki standar untuk nilai rugi-rugi daya maksimal yang diizinkan dalam suatu jaringan. hanya meminimalisir sekecil mungkin agar memperkecil kerugian pada perusahaan.

C. Kondisi Eksiting Penyulang Bencah

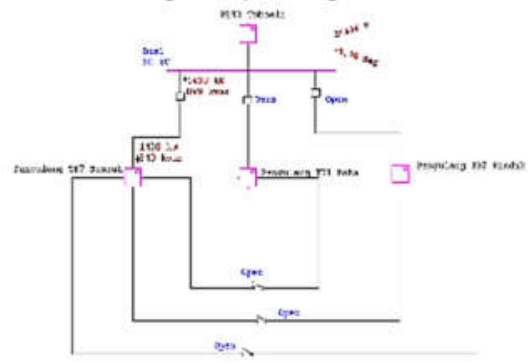

Gambar 7. Hasil Simulasi software kondisi eksisting penyulang Bencah 


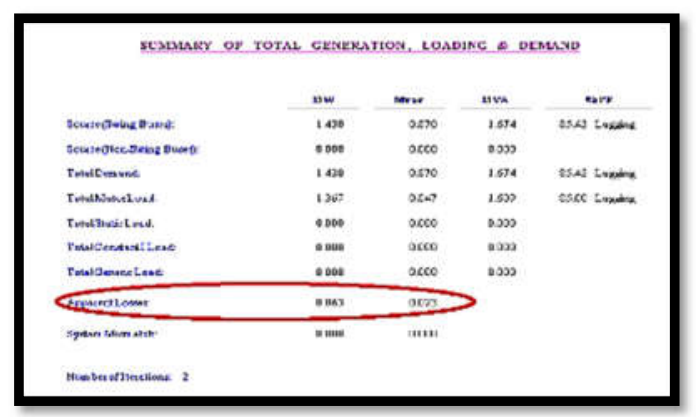

Gambar 8. Summary report kondisi eksisting penyulang Bencah

Dari Gambar 7 dan 8. dapat diketahui dari simulasi summry report pada software penyulang rindikdiperoleh rugi-rugi daya aktif $63 \mathrm{~kW}$ dan rugi daya reaktif 23 kvAr. Rugi-rugi daya tersebut dipengaruhi oleh panjang saluran dan luas panjang kawat penghantar. Nilai rugi-rugi ini relatif tinggi untuk daya yang hilang. Namun PLN sendiri tidak memiliki standar untuk nilai rugi-rugi daya maksimal yang diizinkan dalam suatu jaringan. hanya meminimalisir sekecil mungkin agar memperkecil kerugian pada perusahaan.

\section{Kondisi Eksiting Penyulang Kota}

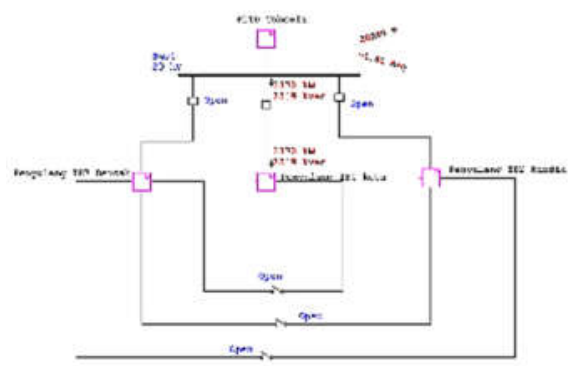

Gambar 9. Hasil Simulasi software kondisi eksisting penyulang Kota

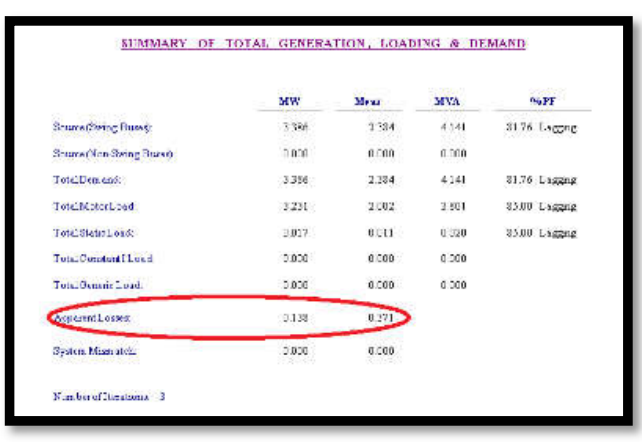

Gambar 10. Summary report kondisi eksisting penyulang Kota

Dari Gambar 9 dan 10 dapat diketahui dari simulasi summry report pada software penyulang rindikdiperoleh rugi-rugi daya aktif $138 \mathrm{~kW}$ dan rugi daya reaktif 371 kvAr. Rugi-rugi daya tersebut dipengaruhi oleh panjang saluran dan luas panjang kawat penghantar. Nilai rugi-rugi ini relatif tinggi untuk daya yang hilang. Namun PLN sendiri tidak memiliki standar untuk nilai rugi-rugi daya maksimal yang di izinkan dalam suatu jaringan. hanya meminimalisir sekecil mungkin agar memperkecil kerugian pada perusahaan.

E. Kondisi Pertama, Kondisi Kedua, dan Kondisi Ketiga Penyulang Penyulang Rindik Manuver Ke Penyulang Bencah Serta Rugi-Rugi Daya

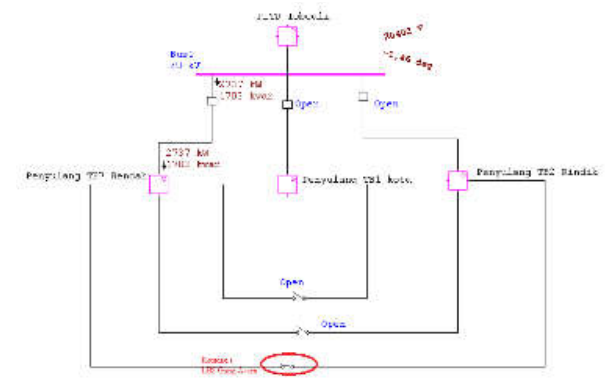

Gambar 11. Hasil simulasi software kondisi pertama penyulang rindik manuver ke penyulang bencah dengan penambahan load break switch (LBS) Gang asem

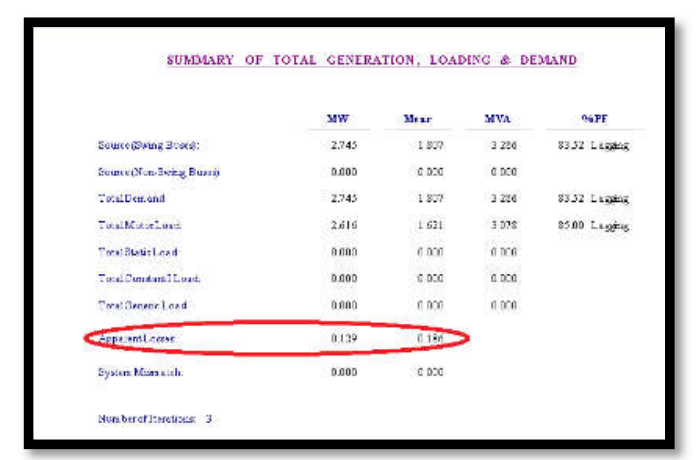

Gambar 12. Summary report kondisi Pertama Penyulang Rindik manuver Penyulang Bencah

Dari Gambar 11 dan 12. dapat diketahui dari simulasi summry report pada software penyulang Rindik manuver ke penyulang Bencah diperoleh rugirugi keseluruhan daya aktif $129 \mathrm{~kW}$ dan rugi daya reaktif 186 kvAr. Rugi-rugi daya tersebut dipengaruhi oleh panjang saluran dan luas panjang kawat 
penghantar. Nilai rugi-rugi ini relatif tinggi untuk daya yang hilang. Namun PLN sendiri tidak memiliki standar untuk nilai rugi-rugi daya maksimal yang di

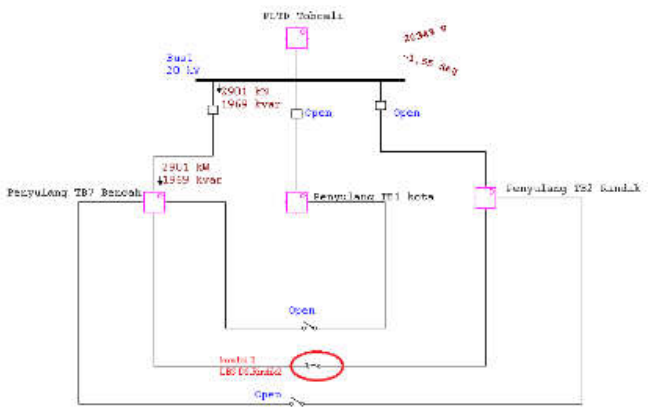

izinkan dalam suatu jaringan . hanya meminimalisir sekecil mungkin agar memperkecil kerugian pada perusahaan.

Gambar 13. Hasil simulasi software kondisi kedua penyulang rindik manuver ke penyulang bencah dengan penambahan load break switch DS. Rindik2

Simulasi Kondisi kedua circuit breaker pada penyulang Rindik dalam kondisi open, sedangkan Load Break Switch DS.Rindik2 dalam kondisi close. sehingga beban pada penyulang Rindik dialihkan ke penyulang Bencah lewat jalur interterkoneksi antara kedua penyulang. Sehingga penyulang Rindik di pasok dari penyulang Bencah. Nilai rugi-rugi daya dapat dilihat pada Gambar 14.

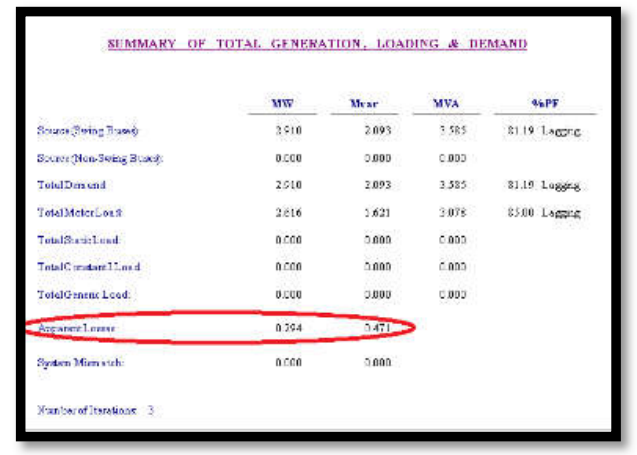

Gambar 14. Summary report kondisi kedua Penyulang Rindik manuver Penyulang Bencah

Dari Gambar 13 dan 14. dapat diketahui dari simulasi summry report pada software kondisi kedua penyulang Rindik manuver ke penyulang Bencah diperoleh rugi-rugi keseluruhan daya aktif $286 \mathrm{~kW}$ dan rugi daya reaktif $453 \mathrm{kvAr}$. Rugi-rugi daya tersebut dipengaruhi oleh panjang saluran dan luas panjang kawat penghantar. Nilai rugi-rugi ini relatif tinggi untuk daya yang hilang. Namun PLN sendiri tidak memiliki standar untuk nilai rugi-rugi

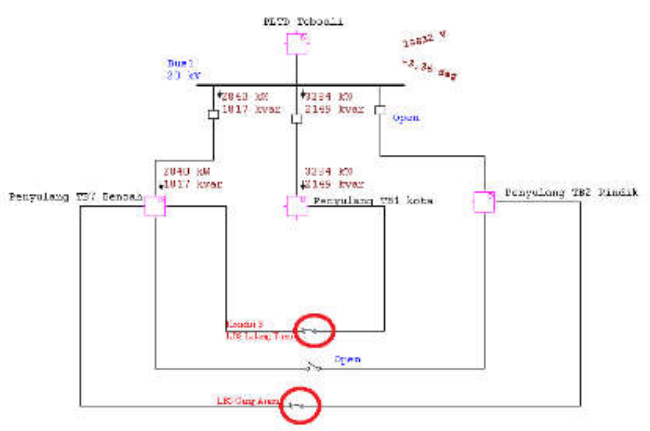

daya maksimal yang di izinkan dalam suatu jaringan. hanya meminimalisir sekecil mungkin agar memperkecil kerugian pada perusahaan.

Gambar 15. Hasil simulasi software kondisi ketiga penyulang rindik manuver ke penyulang bencah dan penyulang Kota dengan penambahan load break switch Lalang tunu dan Gang

Circuit breaker pada penyulang Rindik dalam kondisi open, sedangkan Load Break Switch lalang tunu dan load brek switch pada Gang Asem dalam kondisi close. sehingga beban pada penyulang Rindik dialihkan ke penyulang Bencah dan penyulang kota lewat jalur interterkoneksi antara kedua penyulang. Sehingga penyulang Rindik di pasok dari penyulang

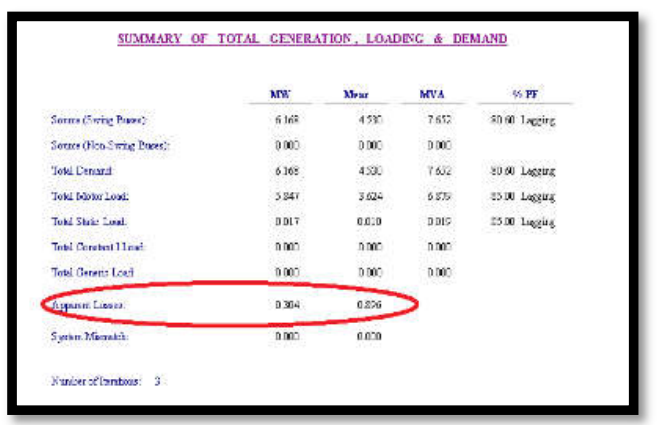

Bencah dan penyulsng Kota. Nilai rugi daya dapat dilihat pada Gambar 16.

Gambar 16. Summary report Penyulang Rindik manuver ke penyulang bencah dan Penyulang Kota

Dari gambar 15 dan 16. dapat diketahui dari simulasi summry report pada software kondisi ketiga penyulang Rindik manuver ke penyulang Bencah dan penyulang Kota diperoleh rugi-rugi keseluruhan daya aktif $304 \mathrm{~kW}$ dan rugi daya reaktif 896 kvAr. Rugirugi daya tersebut dipengaruhi oleh panjang saluran dan luas panjang kawat penghantar. Nilai rugi-rugi ini 
relatif tinggi untuk daya yang hilang. Namun PLN sendiri tidak memiliki standar untuk nilai rugi-rugi daya maksimal yang di izinkan dalam suatu jaringan. hanya meminimalisir sekecil mungkin agar memperkecil kerugian pada perusahaan.

\section{F. Hasil Analisis Perbandingan aliran daya kondisi eksisting}

Tabel 1. Perbandingan aliran daya kondisi eksisting dan analisis perbandingan Setelah maneuver

\begin{tabular}{|c|c|c|c|c|}
\hline \multicolumn{5}{|c|}{ Aliran daya } \\
\hline \multirow[b]{2}{*}{ Kondisi } & \multirow[b]{2}{*}{ Keterangan } & \multicolumn{2}{|c|}{ Rugi daya } & $\begin{array}{l}\text { Tegangan } \\
\text { Terendah }\end{array}$ \\
\hline & & $\begin{array}{c}\text { Daya } \\
\text { aktif } \\
(\mathrm{mw})\end{array}$ & $\begin{array}{c}\text { Daya } \\
\text { reaktif } \\
\text { (mvar) }\end{array}$ & $\mathrm{Kv}$ \\
\hline \multirow{3}{*}{ Eksisting } & Rindik & 0,031 & 0,055 & $\begin{array}{c}20,431 \\
\text { Bus r234 }\end{array}$ \\
\hline & Bencah & 0,063 & 0,023 & $\begin{array}{c}19,720 \\
\text { Bus b72 }\end{array}$ \\
\hline & Kota & 0,138 & 0,371 & $\begin{array}{c}19,848 \\
\text { Bus k14b }\end{array}$ \\
\hline \multirow{4}{*}{$\begin{array}{c}\text { Kondisi } \\
1 \\
\text { Rindik } \\
\text { manuver } \\
\text { ke } \\
\text { bencah }\end{array}$} & & \multirow{4}{*}{0,129} & \multirow{4}{*}{$\begin{array}{c}0,18 \\
6\end{array}$} & \multirow{4}{*}{$\begin{array}{c}19,423 \\
\text { Bus } \\
\text { b72 }\end{array}$} \\
\hline & $\begin{array}{l}\text { Rindik } \\
\text { (open) }\end{array}$ & & & \\
\hline & & & & \\
\hline & $\begin{array}{c}\text { Bencah } \\
\text { (close) }\end{array}$ & & & \\
\hline \multirow{3}{*}{$\begin{array}{c}\text { Kondisi } \\
2 \\
\text { Rindik } \\
\text { manuver } \\
\text { ke } \\
\text { bencah }\end{array}$} & $\begin{array}{l}\text { Rindik } \\
\text { (open) }\end{array}$ & \multirow[b]{3}{*}{0,294} & \multirow[b]{3}{*}{$\begin{array}{c}0,47 \\
1\end{array}$} & \\
\hline & & & & \\
\hline & $\begin{array}{c}\text { Bencah } \\
\text { (close) }\end{array}$ & & & $\begin{array}{c}18,153 \\
\text { bus } \\
\text { b72 }\end{array}$ \\
\hline \multirow{3}{*}{$\begin{array}{c}\text { kondisi } \\
3 \\
\text { Rindik } \\
\text { manuver } \\
\text { ke } \\
\text { bencah } \\
\text { dan kota }\end{array}$} & $\begin{array}{l}\text { Rindik } \\
\text { (open) }\end{array}$ & & & \multirow[b]{2}{*}{$\begin{array}{c}18,769 \\
\text { bus } \\
\text { b72 }\end{array}$} \\
\hline & $\begin{array}{c}\text { Bencah } \\
\text { (close) }\end{array}$ & 0,142 & $\begin{array}{c}0,57 \\
0\end{array}$ & \\
\hline & Kota (close) & 0,137 & $\begin{array}{c}0,25 \\
4\end{array}$ & $\begin{array}{c}19,395 \\
\text { Bus k14b }\end{array}$ \\
\hline
\end{tabular}

Hasil penelitian dan pembahasan adalah penyajian hasil utama secara objektif, tanpa interpretasi, dalam suatu susunan logis dan teratur menggunakan bahasa ilustratif (gambar dan tabel) dan teks. Hasil dan pembahasan seharusnya diorganisasikan dalam suatu seri tabel atau gambar secara berurutan untuk menyajikan temuan utama bertahap dalam tiga bagian: uraian temuan data dan informasi yang terkumpul, analisis serta penjelasan sintesisnya. Sertakan data pendukung yang berupa tabel, grafik, gambar, atau alat bantu lain seperlunya untuk memperjelas dan mempersingkat uraian yang harus diberikan.

\section{KESIMPULAN}

Berdasarkan hasil analisa aliran daya Penyulang Rindik antara kondisi eksisting dan kondisi sesudah manuver maka dapat diambil kesimpulan sebagai berikut:

1. Tegangan ujung pada Penyulang Rindik yaitu sebesar 20,431 kV , rugi-rugi daya pada penyulang Rindik 0,031 MW; kondi eksisting tegangan ujung pada Penyulang Bencah yaitu $19,720 \mathrm{kV}$, rugi-rugi daya pada penyulang Bencah 0,063 MW dan sedangkan kondi eksisting tegangan ujung pada Penyulang Kota yaitu sebesar $19,848 \mathrm{kV}$. rugi-rugi daya pada penyulang Kota 0,138 MW.

2. Tegangan ujung penyulang Bencah yaitu sebesar $19,423 \mathrm{kV}$ dengan rugi-rugi daya yaitu 0,0129 MW dan hasil kondisi manuver kondisi kedua dapat dilihat pada ujung penyulang Bencah yaitu sebesar $18,153 \mathrm{kV}$ dengan rugi-rugi daya yaitu 0,294 MW, dan sedangkan hasil kodisi ketiga dapat dilihat pada ujung penyulang Bencah dan ujung penyulang kota, dilihat dari ujung penyulang Bencah yaitu sebesar $18,769 \mathrm{kV}$ dan tegangan ujung penyulang Kota yaitu sebesar $19,395 \mathrm{Kv}$ dengan rugi-rugi daya keseluruhan yaitu sebesar 0,304 MW.

3. Hasil perbandingan simulasi dari 3 kondisi simulasi manuver yang dilakukan, manuver beban yang menghasilkan tegangan ujung yang baik, serta memiliki rugi-rugi daya yang peling kecil, adalah pada simulasi manuver kondisi pertama yang dimana penyulang Rindik manuver ke penyulang Bencah dengan penambahan Load Brek Switch Gang asem , tegangan dapat dilihat pada ujung pada penyulang Bencah Bus K72 yaitu sebesar 19,423 kV, Serta memiliki rugi-rugi daya sebesar 0,129 MW, yang merupakan rugi daya terkecil dari ketiga simulasi manuver beban yang dilakukan. Sehingga kondisi pemasangan Load break switch yang layak dipasang adalah kondisi manuver beban yang pertama.

\section{REFERENSI}

[1]. H. Y. Abriyanto, F. Arkan, dan R. Kurniawan, "Analisis Rekonfigurasi Jaringan Sistem 20 kV Bangka Untuk Meningkatkan Kualitas Pelayanan 
Pelanggan", Prosiding Seminar Nasional Penelitian dan Pengabdian pada Masyarakat FT UBB Vol.1, 2017.

[2]. D. R. Adikasi, "Analisis Drop Tegangan dan Manuver Jaringan pada Penyulang Bawen 2 dengan ETAB Power Stattion 12.6", Teknik Elektro, Fakultas Teknik Universitas Muhammadiyah Surakarta, 2018.

[3]. K. Fahri, "Analisis Aliran Daya pada Sistem Tenaga Listrik PLN Area Bangka", Jurusan Teknik Elektro, Fakultas Teknik Universitas Bangka Belitung, 2016.

[4]. D. Mujiono, R. Kurniawan, dan F. Arkan, "Analisis Pemecahan Beban Penyulang Anoa Di Muntok Dengan Menggunakan Simulasi ETAB 12.6.0", Prosiding Seminar Nasional Penelitian dan Pengabdian pada Masyarakat FT UBB Vol.1, 2017.

[5]. A. G. Nigara, Y. Primadiyo, "Aliran Daya Sistem Tenaga Listrik Pada Bagian Texturizing di PT.Asia Pasific Fiber tbk Kandal Menggunakan Software ETAP Power Stattion 4.0", Jurnal Teknik Elektro, Vol.7 No.1 pp.7-10, 2015.

[6]. Patmawati, "Analisis Aliran Daya Dan Keandalan Sistem Distribusi Pada Penyulang Kampung Jeruk Garudu Induk Pangkalpinang", Jurusan Teknik Elektro, Fakultas Teknik Universitas Bangka Belitung, 2018.

[7]. I. Y. Pratama, dan S. T. A. Budiman, "Analisis rugi daya saat manuver jaringan dengan etap power station 12.6. Teknik Elektro, Fakultas Teknik Universitas Muhammadiyah Surakarta, 2019.

[8]. Suhadi, dkk., "Teknik Distribusi Tenaga Listrik Jilid 1", Jakarta: Direktorat Pembinaan Sekolah Menengah Kejuruan, 2008.

[9]. W. D. Stevenson, "Analisis Sistem Tenaga Listrik Ed. Keempat”, Bandung: Erlangga, 1983.

[10].Y. A. Widyantoro, “Analisis profil tegangan saat manuver jaringan di penyulang $B W N-2$ dengan ETAP power station 12.6”, Teknik Elektro, Fakultas Teknik Universitas Muhammadiyah Surakarta, 2019. 